\title{
Prevalence of symptomatic urinary tract infections and antimicrobial susceptibility patterns of isolated uropathogens in kohat region of Pakistan
}

\begin{abstract}
Urinary tract infections are commonly distributed infectious diseases. This study is designed to determine the prevalence of symptomatic UTIs and antimicrobial susceptibility patterns of uropathogens to commonly use antibiotics. A total of 500 patients, age ranges 20-90years were included in this study that conducted in Kohat Teaching Hospital of Kohat District, Khyber Pakhtunkhwa, Pakistan. Midstream urine samples were collected from patients of both genders. All samples were cultured aerobically in Blood agar, MaCconkey agar and CLED medium (Oxoid). The identification of isolated bacteria were performed using manual biochemical tests. All uropathogenic isolates were subjected to antimicrobial susceptibility testing. The prevalence of UTIs were $11.6 \%$. The frequency of UTIs was $8.9 \%$ in males and $13.8 \%$ in females. Out of total positive cultures, $20.7 \%(12 / 58)$ were Gram positive bacteria and 79.3(46/58) were Gram negative bacteria. The commonly isolated pathogens are Escherichia coli 24 (41.4\%), Klebsiella pneumoniae $9(15.5 \%)$ and Proteus mirabilis 8 (13.8\%). Most lactose fermenter Gram-ve bacteria were sensitive to Cefepime and all Gram positive isolates were sensitive to Meropenem. In this study, it was concluded that there is marked variation in the prevalence of UTIs (between males and females) and antibiotics susceptibility patterns of uropathogens. Meropenem is appropriate antibiotics to treated UTIs causes by Gram positive bacteria. These data demonstrate that future studies should be focused on the causes of antibiotics resistance to solve this problem.
\end{abstract}

Keywords: antimicrobial, Pakistan, prevalence, urinary tract infection, uropathogen
Volume 3 Issue 3 - 2018

Anwar Ullah,' Syed Rafiq Hussain Shah,' Babiker Saad Almugadam, ${ }^{2}$ Shahida Sadiqui' 'Department of Microbiology, Faculty of Health Sciences, Hazara University, Mansehra, Pakistan

2Department of Microbiology, Faculty of Medical Laboratory Sciences, University of El Imam El Mahdi, Kosti city, Sudan

Correspondence: Anwar Ullah, Department of Microbiology, Faculty of Health Sciences, Hazara university, Mansehra, Pakistan, Tel+923015709168, Email anwarmicrobiologist@gmail.com

Received: June 17, 2018 | Published: July 27, 2018

\section{Introduction}

Urinary tract infection (UTI) is a one of the most frequent and contagious infection. Due to its complexity, it damages various types of delicate organs in the human body such as urethra, ureters and bladder. ${ }^{1}$ UTIs is more common in females especially in pregnant women as a result of anatomical difference and the decrease level of urination during pregnancy. ${ }^{2,3}$ Pregnancy increases bactriuria which leads to pyelonephritis and obstetric such as higher fetal mortality rates, low-birth weight and prematurity. ${ }^{4}$ It has been estimated that about 150 million peoples were diagnosed worldwide for the presence of Gram negative bacteremia which is the significant cause of UTI in all ages specifically in the old age peoples. ${ }^{5}$ Fifteen to twenty percent of the urinary tract infection is caused by Gram positive bacteria and about eighty to eighty five percent is caused by Gram negative bacteria. The mechanisms of pathogenesis depend on the causative agent and its virulence factors. ${ }^{6-9}$

Due to multi-drug Resistant microorganisms there have been great changes occurred in the antimicrobial susceptibility patterns of urinary pathogens. ${ }^{10,11}$ And due to antibiotic-resistant bacteria, the treatment of UTIs become empirical hard so raising the prevalence of infection. ${ }^{12}$ In the world, the unusual development and increasing of multidrug-resistant in bacterial pathogens is a great health problem which is rising day by day in a growing community. ${ }^{13,14}$ In worldwide, for the last two or three decades, hospital acquired UTIs are increased due to the emergence of multidrug resistant uropathogens. ${ }^{15-17}$

According to the geographical location, different antibiotics have different resistance rate and they are directly proportional to the abuse of antibiotics. ${ }^{18}$ The increasing appearance of multidrug resistant
(MDR) bacteria is has been exaggerated over the time due to increase use of antibiotics in many sectors such as agricultural, medical and veterinary. ${ }^{19,20}$ The main factors which leads to antibiotics resistance include the incorrect investigation and drugs abuse..$^{21}$ In some time the treatments of simple infection can become complicated or impossible due to bacterial resistant strains. This study is designed to determine the prevalence of symptomatic UTIs and antimicrobial sensitivity patterns of uropathogens in District Kohat of Pakistan.

\section{Materials and methods}

\section{Study design, area and duration}

This is cross sectional hospital base study carried out from June to December 2015 in Kohat Teaching Hospital of Kohat District, Khyber Pakhtunkhwa, Pakistan.

\section{Study population}

All patients with symptomatic UTIs, ages ranging 20-90years and belonged to District Kohat of Pakistan were fulfill the inclusion criteria.

\section{Sampling}

A total of 500 midstream urine samples were collected from patients of both genders, those attended Kohat Teaching Hospital with the symptoms of UTIs.

\section{Methodology}

All urine samples were cultured on Blood agar, MaCconkey agar and CLED medium (Oxoid). ${ }^{22}$ The significant growth bacteria was 
processed for identification and antibiotics susceptibility testing.

\section{Isolation and identification:}

Each specimen was thoroughly mixed by inverting the container 2-3times and inoculated into culture mediums. The culture plates were incubated at $37^{\circ} \mathrm{C}$ for 24 hours. In case of no growth, further incubation was carried out for additional 24hour. More than $10^{5}$ colony forming unit per $\mathrm{ml}$ was considering as the significant level of bacteriuria. The identification of isolates were performed on the base of gram reaction, colonial morphology and biochemical characterization. ${ }^{22}$

\section{Antibiotic susceptibility testing:}

The antibiotic susceptibility testing was performed by Kirby Bauer's disc diffusion technique (Bauer et al., 1966) as suggested by clinical and laboratory standard institute. ${ }^{23}$ The zone of inhibition was calculated and interpreted using the standard chart and the organisms were reported as susceptible, intermediate or resistant accordingly. Different antibiotic discs (Oxoid) were used in this study and these were Ceftriaxone (CRO), Ceftazidime (CAZ), Cefepime (FEP), Meropenem (MRP), and Ciprofloxacin (CIP). Plus Augmentin (AUG) and Levofloxacin (LEV), only for Gram-ve bacteria. E. coli ATCC 252395 was used as control strain.

\section{Ethical statement}

This study was undertaken with the approval of Hazara University and conducted according to the declaration of Helsinki and with particular ethical standards of Hazara University. Verbal consent was taken from each participant.

\section{Data analysis}

All data were analyzed with SPSS software version 17. Chi squire test was performed and $\mathrm{P}$ value less than 0.05 was considered statistically significant.

\section{Result}

\section{Prevalence of UTIs}

The current study was conducted on 500 patients of different gender (Males and females) and their corresponding ratio was 225:275 (M:F, 45\%: 55\%), in district Kohat of Pakistan. A total of $58(11.6 \%)$ urine samples were showed the significance growth of uropathogenic bacteria. The prevalence of UTIs in males was $8.9 \%(20 / 58)$ and in females was $13.8 \%(38 / 58)$, See Figure 1.

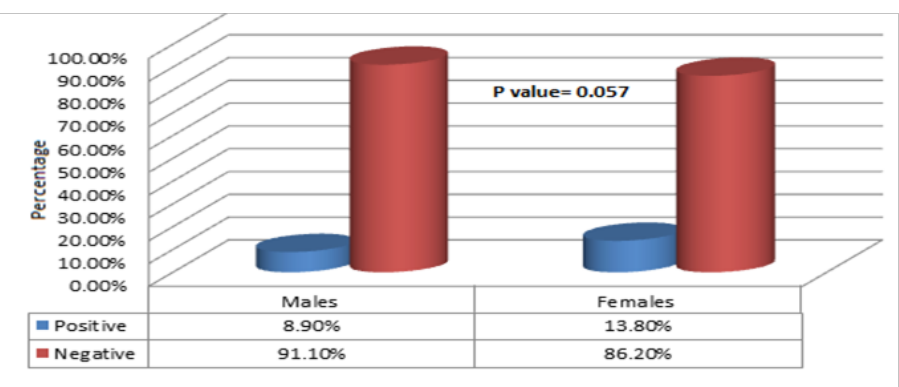

Figure I The prevalence of UTIs in gender.

\section{The frequency of commonly isolated bacteria}

Out of total positive cultures, $20.7 \%$ (12/58) were Gram positive bacteria and 79.3(46/58) were Gram negative bacteria. The most prevalent uropathogenic bacteria were Escherichia coli 24 (41.4\%), Klebsiella pneumoniae $9(15.5 \%)$ and Proteus mirabilis 8 (13.8\%), Table 1.

Table I Frequency of isolated uropathogens

\begin{tabular}{llll} 
Name of bacteria & $\begin{array}{l}\text { Number of } \\
\text { isolates }\end{array}$ & Percentage & P value \\
\hline Escherichia coli & 24 & $41.4 \%(24 / 58)$ & \\
Staph. aureus & 6 & $10.34 \%(6 / 58)$ & \\
Klebsiella pneumoniae & 9 & $15.5 \%(9 / 58)$ & 0.000 \\
Proteus mirabilis & 8 & $13.8 \%(8 / 58)$ & \\
P.aeruginosa & 5 & $8.62 \%(5 / 58)$ & \\
S. Saprophyticus & 6 & $10.34 \%(6 / 58)$ & \\
Total & 58 & &
\end{tabular}

\section{Antibiotics susceptibility of urinary isolates}

The emergence of drugs resistance among urinary isolates to commonly use antibiotics has been observed (Figure 2), and only cefepime and Meropenem are showed a great value against uropathogens. As displayed in Table 2, in our current study the highly prevalent uropathogenic bacteria $E$. coli was showed the highest sensitivity $(91.7 \%)$ to cefepime and lowest sensitivity $(12.5 \%)$ to ciprofloxacin, similarly the $\mathrm{K}$. pneumoniae showed the highest sensitivity $(88.9 \%)$ to Augmentin and the lowest sensitivity (22.2\%) to ceftazidime. The P. mirabilis was $87.5 \%$ sensitive to Meropenem, while it was showed low sensitivity $(12.5 \%)$ to cefepime. The highest sensitivity rate which was showed by $P$. aeruginosa was $80 \%$ against cefepime and the lowest sensitivity rate was 20\% (against ceftazidime). All S. aureus and S. saprophyticus isolates were sensitive to Meropenem. Hindered percent of resistant to ceftazidime was observed in S. saprophyticus isolates and same percentage of resistant to ciprofloxacin was detected in S. aureus isolates, Table 3.

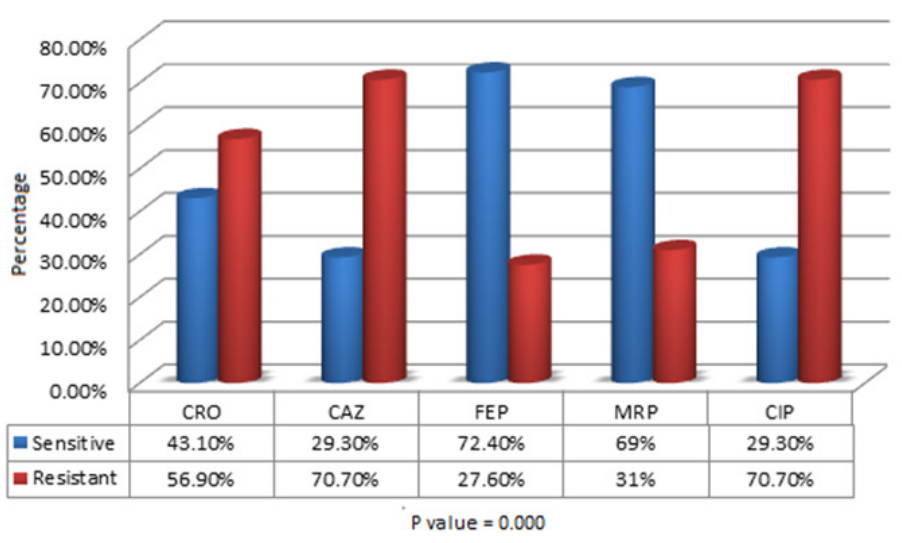

Figure 2 The susceptibility of urinary pathogens to commonly use antibiotics. 
Table 2 Antibiotics susceptibility profile of gram negative isolates

\begin{tabular}{|c|c|c|c|c|c|c|}
\hline \multicolumn{2}{|c|}{ Antibiotics } & \multicolumn{5}{|l|}{ Isolate } \\
\hline & & E. coli & K. pneumoniae & P. aeruginosa & P. mirabilis & Total \\
\hline \multirow{2}{*}{ CRO } & Sensitive & $25 \%(6 / 24)$ & $44.4 \%(4 / 9)$ & $60 \%(3 / 5)$ & $50 \%(4 / 8)$ & $37 \%(17 / 46)$ \\
\hline & Resistant & $75 \%(18 / 24)$ & $55.6 \%(5 / 9)$ & $40 \%(2 / 5)$ & $50 \%(4 / 8)$ & $63 \%(29 / 46)$ \\
\hline \multirow{2}{*}{ AUG } & Sensitive & $50 \%(12 / 24)$ & $88.9 \%(8 / 9)$ & $40 \%(2 / 5)$ & $62.5 \%(5 / 8)$ & $58.7 \%(27 / 46)$ \\
\hline & Resistant & $50 \%(12 / 24)$ & $11.1 \%(1 / 9)$ & $60 \%(3 / 5)$ & $37.5 \%(3 / 8)$ & $41.3 \%(19 / 46)$ \\
\hline \multirow{2}{*}{ CAZ } & Sensitive & $33.3 \%(8 / 24)$ & $22.2 \%(2 / 9)$ & $20 \%(1 / 5)$ & $37.5 \%(3 / 8)$ & $30.4 \%(14 / 46)$ \\
\hline & Resistant & $66.7 \%(16 / 24)$ & $77.8 \%(7 / 9)$ & $80 \%(4 / 5)$ & $62.5 \%(5 / 8)$ & $69.6 \%(32 / 46)$ \\
\hline \multirow{2}{*}{ MRP } & Sensitive & $50 \%(12 / 24)$ & $66.7 \%(6 / 9)$ & $60 \%(3 / 5)$ & $87.5 \%(7 / 8)$ & $60.9 \%(28 / 46)$ \\
\hline & Resistant & $50 \%(12 / 24)$ & $33.3 \%(3 / 9)$ & $40 \%(2 / 5)$ & $12.5 \%(1 / 8)$ & $39.1 \%(18 / 46)$ \\
\hline \multirow{2}{*}{ LEV } & Sensitive & $62.5 \%(15 / 24)$ & $44.4 \%$ (4/9) & $60 \%(3 / 5)$ & $62.5 \%(5 / 8)$ & $58.7 \%(27 / 46)$ \\
\hline & Resistant & $37.5 \%(9 / 24)$ & $55.6 \%(5 / 9)$ & $40 \%(2 / 5)$ & $37.5 \%(3 / 8)$ & $41.3 \%(19 / 46)$ \\
\hline \multirow{2}{*}{ FEP } & Sensitive & $91.7 \%(22 / 24)$ & $77.8 \%(7 / 9)$ & $80 \%(4 / 5)$ & $12.5 \%(1 / 8)$ & $73.9 \%(34 / 46)$ \\
\hline & Resistant & $8.3 \%(2 / 24)$ & $22.2 \%(2 / 9)$ & $20 \%(1 / 5)$ & $87.5 \%(7 / 8)$ & $26.1 \%(12 / 46)$ \\
\hline \multirow{2}{*}{ CIP } & Sensitive & $12.5 \%(3 / 24)$ & $44.4 \%(4 / 9)$ & $40 \%(2 / 5)$ & $50 \%(4 / 8)$ & $28.3 \%(13 / 46)$ \\
\hline & Resistant & $87.5 \%(2 \mathrm{I} / 24)$ & $55.6 \%(5 / 9)$ & $60 \%(3 / 5)$ & $50 \%(4 / 8)$ & $71.7 \%(33 / 46)$ \\
\hline
\end{tabular}

Table 3 Antibiotics susceptibility profile of gram positive isolates

\begin{tabular}{|c|c|c|c|c|}
\hline \multirow{2}{*}{ Antibiotic } & \multirow{2}{*}{ Susceptibility result } & \multicolumn{3}{|l|}{ Isolate } \\
\hline & & S. saprophyticus & S. aureus & Total \\
\hline \multirow{2}{*}{ CRO } & Sensitive & $50 \%(3 / 6)$ & $83.3 \%(5 / 6)$ & $66.7 \%(8 / / 2)$ \\
\hline & Resistant & $50 \%(3 / 6)$ & $16.7 \%(1 / 6)$ & $33.3 \%(4 / 12)$ \\
\hline \multirow{2}{*}{ CAZ } & Sensitive & $0 \%(0 / 6)$ & $50 \%(3 / 6)$ & $25 \%(3 / 12)$ \\
\hline & Resistant & $100 \%(6 / 6)$ & $50 \%(3 / 6)$ & $75 \%(9 / 12)$ \\
\hline \multirow{2}{*}{ FEP } & Sensitive & $83.3 \%(5 / 6)$ & $50 \%(3 / 6)$ & $66.7 \%(8 / 12)$ \\
\hline & Resistant & $16.7 \%(1 / 6)$ & $50 \%(3 / 6)$ & $33.3 \%(4 / 12)$ \\
\hline \multirow{2}{*}{ MRP } & Sensitive & $100 \%(6 / 6)$ & $100 \%(6 / 6)$ & $100 \%(12 / 12)$ \\
\hline & Resistant & $0 \%(0 / 6)$ & $0 \%(0 / 6)$ & $0 \%(0 / 12)$ \\
\hline \multirow{2}{*}{ CIP } & Sensitive & $33.3 \%(2 / 6)$ & $0 \%(0 / 6)$ & $16.7 \%(2 / 12)$ \\
\hline & Resistant & $66.7 \%(4 / 6)$ & $100 \%(6 / 6)$ & $83.3 \%(10 / / 2)$ \\
\hline
\end{tabular}

\section{Discussion}

Urinary tract infection (UTI) is a one of the most common infections worldwide and it account for $1-2 \%$ of all consultation. ${ }^{24}$ It has been estimated that more than 6million outpatient visits and 300,000 hospital stays every year are due to UTIs. Approximately $10 \%$ of humans will have a UTI at some time during their lives. ${ }^{25}$

Our study was found the prevalence of UTI is $11.6 \%$ among symptomatic patients; and $8.9 \%$ in males and $13.8 \%$ in females. Similar studies has been conducted in different countries includes Mandokhail et al., ${ }^{26}$ Prakash D et al. ${ }^{27}$ and Patil et al., ${ }^{28}$ studies which reported the prevalence of UTIs were $60.63 \%, 53.82 \%$, and $49 \%$, respectively. ${ }^{26-28}$ Several reports have indicated that the prevalence of UTIs is more in females than males. John MS et al., ${ }^{29}$ reported the rate of culture positivity in females was $91.6 \%$ and in males was $40.3 \%{ }^{29}$ Also Prakash et al., ${ }^{27}$ are found the prevalence of UTIs was significantly higher in females $(73.57 \%)$ than in males $(35.14 \%) .{ }^{27}$
However, all these prevalence are highest than our study result, but they agreed in the increase of UTIs in females than males that is previously confirmed in many others studies.

Among the total of isolated bacteria, we found the prevalence of Gram positive bacteria and Gram negative bacteria were $20.7 \%$ and $79.3 \%$, respectively. And the most prevalent uropathogenic bacteria were Escherichia coli $(41.4 \%)$, Klebsiella pneumoniae $(15.5 \%)$, Proteus mirabilis $(13.8 \%)$, S. saprophyticus $(10.34 \%)$, Staphylococcus aureus (10.34\%), and P. aeruginosa (8.62\%). These results, indicate Gram negative are more commonly implicated in UTIs in this area of Pakistan. Previously, Prakash D et al., (2013) study was found the prevalence of Gram negative bacteria (90.32\%) were higher than Gram positive $(9.68 \%)$; and the most frequently isolated urinary pathogen is Escherichia coli (42.58\%), followed by Klebsiella pneumoniae (18.71\%) and Pseudomonas aeruginosa (12.90\%) [27]. Similar results, Also were reported by Patil S et al., (2013) study, who found out of the 48 positive culture, $83.3 \%$ (40/48) 
were gram negative bacteria and $16.7 \%(8 / 48)$ were Gram positive bacteria; and $65 \%$ of isolated pathogens are E. coli. ${ }^{28}$

In this work, we observed the emergence of antibiotics resistant. The sensitivity of isolated bacteria to Ceftriaxone, Ceftazidime, Cefepime, Meropenem, and Ciprofloxacin were 43.1\%, 29.3\%, $72.4 \%, 69 \%$ and $29.3 \%$, respectively. There is marked difference in susceptibility of Gram+ve and -ve bacteria; and their members to different antibiotics. Similarly results has been reported by Laghawe A et al., (2015) study that was found Gram+ve bacteria are less Sensitive to Ciprofloxacin and Meropenem than Gram-ve. ${ }^{30}$ Preventing the dispensing of medicines without prescription and proper use of it by patients can aid in control of antibiotics resistance in this area.

\section{Conclusions}

Urinary tract infections are a one of commonly distributed infection. Recently the emergence of drugs resistance has been observed among urinary isolates. In this study, it was concluded that the resistance of antimicrobial agent among uropathogens was increased and there is marked variation in the antibiotics susceptibility patterns of uropathogens. Meropenem is appropriate antibiotic to treated UTIs causes by Gram positive bacteria. These data demonstrate that future studies should be focused on the causes of antibiotics resistance to find the solves for this problem; and in implementation of health education to prevent drugs abuse in communities.

\section{Acknowledgements}

Authors would like to thanks the participant patients and staff of Kohat Teaching Hospital.

\section{Authors contributions}

$\mathrm{AU}$ was contributed for designing of study; and collection and laboratory analysis of samples. SHS was supervised the work. BSA was analyzed the data and wrote the article. AU, SS and SHS were revised the article.

\section{Conflicts interest}

The author declares no conflict interest.

\section{References}

1. Al -Dujiaily AA. Urinary tract infection during pregnancy in Tikrit. $J$ Tikrit. 2000;6:220-224.

2. Awaness A, Al-Saadi MG, Aadoas S. Antibiotics resistance in recurrent urinary tract infection. Kufa medical journal. 2000;3:159.

3. Lucas M, Cunningharm F. Urinary infection in pregnancy. Clin Obstet Gynecol. 1993;36:855-868.

4. Connolly A, Thorp J. Urinary Tract Infection in pregnancy. Urologic clinic of North America. 1999;26(4):776-787.

5. Ahmadzadeh A, Askarpour S. Assocition of urinary tract abnormalities in children with first urinary tract infection. Pakistan Journal of Medical Sciences. 2007;23(1):88-91.

6. Bakhsh MS, Ramazan M, Khan MG. In vitro study of various antimicrobial agents against urinary tract isolates. Journal of Research in science teaching. 2006;22:28-32.

7. Bajaj JK, Karyakarte PR, kulkarni DJ, et al. Changing aetiology of urinary tract infections and emergence of drug resistance as a major problem. Journal Communication Disorders. 1999;31(3):181-184
8. Ehinmidu O. Antibiotics susceptibility patterns of urine bacterial isolates in Zaria, Nigeria. Trop Journal of Pharmaceutical Research. 2003;2:223228 .

9. Elder JS, Behrman ER, Kliegman MR. "Urinary tract infection Nelson Textbook of Pediatrics". 17th ed. 2004.

10. Stamm WE, Stapleton AE. Approach to the patient with urinary tract infection. In Infectious Diseases. 2 edition. Journal of infectious diseases. 1998;22:1270-1272

11. Mohammed AS, Asad U.K. Etiology and antibiotic resistance patterns of community-acquired urinary tract infections in J N M C Hospital Aligarh, India. International journal of Clinical Microbiology and Antimicrobial. 2007;6:4.

12. Steinke DT, Seaton RA, Phillips G, et al. Prior trimethoprim use and trimethoprim -resistant urinary tract infection. a nested case - control study with multivariate analysis for other risk factors. Journal of Antimicrobial Chemotherapy .2001;47(6):781-787.

13. Luzzaro F, Brigante G, Andrea D, et al. Spread of multidrug -resistant Proteus mirabilis isolates producing an AmpC-type beta -lactamase. epidemiology and clinical management". International Journal of Antimicrobial Agents. 2009;33(4):328-333.

14. D'Andrea MM, Literacka EA, Zioga T, et al. Evolution and spread of a multidrug -resistant Proteus mirabilis clone with chromosomal AmpC type cephalosporinases in Europe. Journal of Antimicrobial Agents and Chemotherapy. 2011;55(6):2735-2742.

15. Moges FG, Mengistu, Genetu A. Multiple drug resistance in urinary pathogens at Gondar College of Medical Sciences Hospital, Ethiopia. East African Medical Journal. 2002;79(8):415-419.

16. Metlay JP, Shea JA, Crossette LB, et al. Tensions in antibiotic prescribing: pitting social concerns against the interests of individual patients. Journal of General Internal Medicine. 2002;17(2):87-94.

17. Barlow G, Nathwani D. Is antibiotic resistance a problem? A practical guide for hospital clinicians. Postgraduate Medical Journal. 2005;81(961):680 692 .

18. Gupta K, Sahm DF, Mayfield D, et al. Antimicrobial resistance among uropathogens that cause community acquired urinary tract infections in women, A nationwide analysis. Journal of Clinical Infectious Diseases. 2001;33:89-94.

19. Ahmed MO, Clegg PD, Williams NJ, et al. Antimicrobial resistance in equine faecal Escherichia coli isolates from North West England". International journal of Clinical Microbiology and Antimicrobials. 2012;9:12.

20. White GD. Antimicrobial resistance in pathogenic Escherichia coli from animals. In: Aarestrup FM, et al. editors. Antimicrobial Resistance in bacteria of animal origin. 2006. 12:145-166.

21. Banzon JA, Velasco J. Coconut production and utilization. Philippines: Philippine coconut research and development foundation". Inc. Publication; 1982. 13:349 p

22. Koneman EW, Allens SO, Janda WM. Colour Atlas and Textbook for Diagnostic Microbiology. 4th ed. Philadelphia: JB Lippincott Company; He Enterobactericeae. 2006. 61-402.

23. Clinical and Laboratory Standards Institute. NCCLS performance standards for antimicrobial susceptibility testing. 15th informational supplement. CLSI/NCCLS M 100-S15. Philadelphia: Clinical and Laboratory Standards institute; 2005.

24. Suliman S, Beliela MH, Hamza H. Dialysis and transplantation in Sudan. Saudi Kidney Dis Transplant Bull. 1995;6(3):312-314.

25. Schwartz BF, Stoller ML. Nonsurgical management of infection -related renal calculi. Urol Clin North Am. 1999;26(4):765-768. 
26. Mandokhail F, Jamil N, Riaz M. Prevalence of Symptomatic and Asymptomatic Urinary Tract Infection in Humans. World Journal of Zoology. 2015;10(4):310-312.

27. Prakash D, Saxena RS. Distribution and Antimicrobial Susceptibility Pattern of Bacterial Pathogens Causing Urinary Tract Infection in Urban Community of Meerut City, India. ISRN Microbiology. 2013;2013:13.

28. Patil S, Mahale K, Shetty P, et al. Antibiotic susceptibility pattern of urinary isolates from a tertiary care hospital with special reference to Gram negative bacteria. IOSR-JJDMS. 2013;12(1):49-51.
29. John MS, Meenakshi K, Lakshmi PM, et al. Prevalence and Distribution of Bacterial Pathogens Causing Urinary Tract Infections in Humans: A Study from Tertiary Care Hospital in AP, India. Int J Curr Microbiol App Sci. 2015;4(2):251-257.

30. Laghawe A, Tripathi A, Saxena SB. Aetiology of Urinary Tract Infection and antimicrobial susceptibility pattern of urinary isolates in tertiary care hospital in Central India: A retrospective analysis. Int J Curr Microbiol App Sci. 2015;4(4):962-970. 